\title{
The Private Healthcare Sector in Johor: Trends and Prospects
}

\author{
By Meghann Ormond and Lim Chee Han
}

\section{EXECUTIVE SUMMARY}

- The future of the private healthcare in Johor and in the Iskandar Malaysia (IM) special economic zone in particular is intimately tied to larger property developments and trends in the region, both because private healthcare developers are increasingly the same as property developers and because IM's future population growth relies heavily on corporate settlement in IM and the jobs that such settlement generates. Volatility in corporate investment and settlement in IM may have significant consequences for the sector's development.

- The Federal and Johor State Governments intend to turn IM into a world-class private healthcare destination for local residents and foreign visitors alike. A range of strategies and policies have been launched to develop IM's medical care, aged care, and lifestyle and well-being sectors.

- It is essential to track the impact of federal and regional fiscal incentives for private healthcare development and monitor actual demand for private sector capacity in order to assess the value and utility of such incentives, especially given the potential for such incentives policies to promote the generation of excessive private sector hospital and clinical capacity if left unchecked.

- Private healthcare providers in the region depend mostly on local residents as their consumer base because Johor and IM are not (yet) significant medical tourism destinations. Given the current rate of expansion of existing hospitals and construction of new ones in Johor and specifically in IM, local demand must be secured via measures that increase the Johor household income base, foster 
interstate migration, attract higher income talent in larger numbers to live in the region, and improve quality of life in the region.

- To strengthen medical tourism, private players - both large and small - require greater coordination and cooperation at the regional level in promoting medical tourism and in setting up centres of excellence and medical tourist-friendly services that cater to the actual needs of international patients. 